\title{
Perancangan IoT (Internet of Things) pada Sistem Irigasi Tanaman Cabai
}

\author{
Adimas Ketut Nalendra ${ }^{1}$, M. Mujiono ${ }^{2}$ \\ ${ }^{1,2}$ Administrasi Server dan Jaringan Komputer, Akademi Komunitas Negeri Putra Sang Fajar \\ Blitar \\ E-mail: *11dimas@akb.ac.id, 2jono@akb.ac.id
}

\begin{abstract}
Abstrak - Air merupakan aspek yang penting dalam aspek kehidupan. Dalam bidang pertanian menjadi komponen utama pada fotosintesis dan transportasi nutrisi dari dalam tanah ke tanaman. Biasanya petani memberikan air dua kali dalam sehari di waktu biasa, tetapi di saat tertentu membutuhkan air yang berlebih untuk menjaga kelembapan tanah. Pada tanaman cabai kebutuhan kelembapan tanah sekitar $60 \%$ sampai $80 \%$ agar tanaman bisa tumbuh dengan maksimal. Teknologi internet of things (IoT) dapat membantu petani untuk mendeteksi kebutuhan air yang ada di dalam tanah. Dengan teknologi IoT juga dapat membantu dalam proses irigasi pengairan dengan cara mematikan atau menyalakan pompa secara otomatis. Metode pengembangan sistem internet of things menggunakan Prototyping, dengan pendekatan ini dapat mengetahui dengan baik kebutuhan pengguna dan analis hasil pengembangan sistem dengan cepat. Perangkat IoT yang digunakan untuk membentuk sistem ini meliputi NodeMCU, sensor kelembapan tanah dan aplikasi berbasis mobile sebagai perangkat lunak control perangkat IoT. Sistem Internet of Things (IoT) dapat membantu sistem irigasi pada tanaman cabai untuk menjaga kelembapan tanah di angkat $60 \%$ sampai $80 \%$.
\end{abstract}

Kata Kunci - Internet of Things, IoT, NodeMCU, cabai, sensor

Abstract - Water is an important aspect in aspects of life. In agriculture it is a major component of photosynthesis and transportation of nutrients from the soil to plants. Usually farmers provide water twice a day on a regular basis, but at certain times require excess water to maintain soil moisture. In chili plants, humidity needs around $60 \%$ to $80 \%$ so that plants can grow to the maximum. Internet of things (IoT) technology can help farmers to support the water needs that are in the soil. With IoT technology it can also help in the irrigation process by releasing or managing pumps automatically. The method of developing an internet of things system uses Prototyping, with this approach being able to know well the needs of users and analysts of the results of system development quickly. The IoT device used to make this system is equipped with NodeMCU, a humidity sensor and a mobile based application as an IoT device control software. The Internet of Things (IoT) system can help the irrigation system in chilli plants to ensure the safety of the soil is raised $60 \%$ to $80 \%$.

Keywords - Internet of Things, IoT, NodeMCU, cabai, sensor

\section{PENDAHULUAN}

Air sangatlah penting bagi seluruh aspek kehidupan . Diantaranya dalam bidang pertanian, air berfungsi sebagai komponen utama pada fotosintesis dan sebagai pengatur suhu pada tumbuhan agar stabil. Hampir seluruh proses perkembangan tumbuhan memerlukan air. Air memberikan efek lembab pada tanah yang dapat membantu pertumbuhan tanaman.

Pada umumnya tanaman membutuhkan air dua kali sehari yaitu pada pagi hari dan sore hari[1]. Karena Cuaca di Indonesia khususnya di wilayah Kabupaten Blitar sering tidak menentu, apalagi kondisi wilayah Kabupaten Blitar memiliki wilayah mulai pegunungan sampai ke dataran rendah berbatasan dengan Samudra Hindia. Oleh karena itu mempengaruhi tingkat kelembapan pada tanah. Pada saat cuaca panas membuat kelembapan tanah rendah sedangkan pada saat hujan 
kelembapan tanah menjadi tinggi[9]. Sehingga tingkat kelembapan tanah menjadi sulit untuk di kontrol.

Di Indonesia tanaman cabai merupakan tanaman favorit petani untuk di tanam. Tanaman tabai memberikan efek ekonomi yang tinggi karena kebutuhan akan cabai di Indonesia sangat tinggi. Tingkat produksi tanaman cabai di Indonesia tergolong sangat rendah rata-rata produksi mencapai 6,7 ton per hektar. Salah satu faktor rendahnya produksi cabai adalah cuaca sehingga mempengaruhi tingkat kelembapan tanah.

Dengan perkembangan teknologi saat ini tingkat kelembapan tanah dapat di kontrol dengan penyiraman yang dilakukan secara otomatis atau sering disebut dengan Internet of Things (IoT). Internet of Things (IoT) memungkinkan semua benda dapat berkomunikasi satu sama lain melalui internet[2]. Adanya IoT dapat mengubah kegiatan pertanian khususnya sistem irigasi pada tanaman cabai tanpa harus berada pada suatu lokasi tempat instalasi perangkat. Sehingga ini menjadikan solusi untuk menjaga kelembapan tanah.

Perangkat inti dari internet of thing ini adalah NodeMCU. NodeMCU merupakan perangkat kecil open source yang di lengkapi wifi, sehingga memudahkan kita untuk mengontrol dan monitoring secara nirkabel[3]. Daya yang digunakan oleh mikrokontroller ini adalah 3,3V dan mempunyai output yang juga sebesar 3,3V. Untuk menyalakan pompa menggunakan modul relay. Modul relay adalah saklar(switch) yang dioperasikan secara elektromagnetik yang terdiri dari dua bagian utama yakni Coil dan mekanikal. Kemudian untuk melakukan penyiraman menggunakan pompa air. Pompa air adalah mesin untuk menggerakan fluida.

Konsep internet of things mampu menghasilkan sistem monitoring yang efektif dan efesien karena tidak terkendala dengan jarak sehingga pemilik tanaman dapat melakukan monitoring terhadap tanaman[10]. Sehingga penggunaan Internet of Things ini dapat membantu petani untuk menanam tanaman cabai.

\section{METODE PENELITIAN}

\subsection{Metodologi Penelitian}

Pada penelitian perancangan IoT (Internet of Things) pada sistem irigasi tanaman Cabe ini, peneliti menggunakan pendekatan atau metodologi prototyping. Pendekatan prototyping ini dipilih agar pengembang perangkat lunak dapat mengetahui dengan baik apa yang diinginkan pengguna dengan tidak meninggalkan kaidah serta landasan teknis pengembangan perangkat lunak, yang pada akhirnya dihasilkan sebuah perangkat lunak yang sesaui dengan kebutuhan pengguna[4][14]. Tahapan dalam metodologi prototyping dapat dilihat pada gambar 1 .

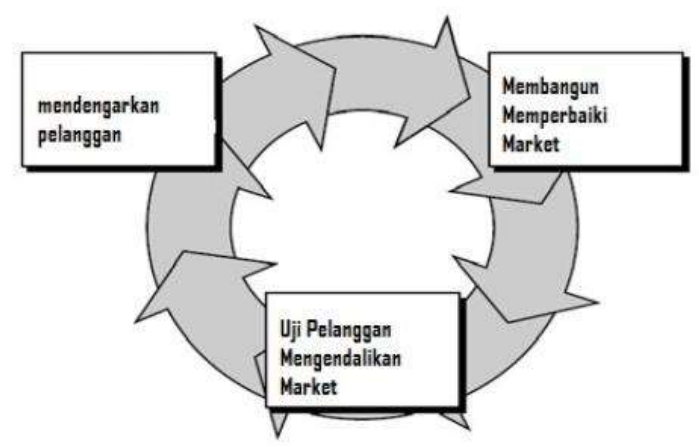

Gambar 1. Tahapan Metodologi Prototyping.

(Sumber : webreferensi.com)

Listen to customer merupakan tahap pertama, yang dilakukan dengan mendengarkan pengguna atau pelanggan untuk menganalisa kebutuhan dari pengguna tersebut. Hal - hal yang perlu dipertimbangkan dalam tahapan ini adalah business process dan permasalahan - permasalahan yang dihadapi pengguna[4][12]. Build or revise mock-up merupakan tahapan dalam usaha untuk mendesain dan membangun perangkat lunak dengan cepat yang disesuaikan dengan kebutuhan pengguna[4][11]. Untuk menggabarkan desain perangkat lunak yang akan dibangun, pada 
penelitian ini digambarkan desain arsitektur dari perangkat lunak, desain interaksi sistem dengan user serta desain mock-up untuk memberikan gambaran perangkat lunak dengan jelas. Customer test-drives mock-up merupakan proses evaluasi oleh pengguna terhadap perangkat lunak yang telah dibangun sehingga didapatkan perangkat lunak yang benar - benar bermanfaat bagi pengguna[4].

\subsection{Studi Literatur}

\subsubsection{Tanaman Cabai}

Tanaman cabai merah (Capsicum annuum L.) adalah tumbuhan perdu yang berkayu, dan buahnya berasa pedas yang disebabkan oleh kandungan kapsaisin. Di Indonesia tanaman tersebut dibudidayakan sebagai tanaman semusim pada lahan bekas sawah dan lahan kering atau tegalan. Namun demikian, syarat-syarat tumbuh tanaman cabai merah harus dipenuhi agar diperoleh pertumbuhan tanaman yang baik dan hasil buah yang tinggi. Potensi hasil cabai derah sekitar 12$20 \mathrm{t} /$ ha.[5]

Cabai merah termasuk tanaman yang tidak tahan terhadap kekeringan, tetapi juga tidak tahan terhadap genangan air. Air tanah dalam keadaan kapasitas lapang (lembab tetapi tidak becek) sangat mendukung pertumbuhan dan perkembangan tanaman cabai merah. Masa kritis tanaman ini terhadap kebutuhan air adalah saat pertumbuhan vegetatif cepat, pembentukan bunga dan buah (Welles 1990). Dari hasil penelitian diketahui bahwa kelembaban tanah yang ideal untuk pertumbuhan dan hasil cabai merah berkisar antara 60-80\% kapasitas lapang.[5]

Penelitian dilakukan di wilayah Kabupaten Blitar tepatnya di desa binangun yang mempunyai topografi wilayah dataran tinggi yang berbatasan langsung dengan Samudra Hindia. Data di ambil pada bulan Januari 2020 sampai bulan Maret 2020. Data diambil selamat tiga bulan sesuai dengan umur tanamnan Cabe yang sudah mulai berbuah dan bisa dipanen setelah berumur 2,5-3 bulan sejak bibit ditanam[10].

\subsubsection{Internet of Things}

Internet of things merupakan sebuah penggabungan kata dari internet dan things arti sebuah kata dari internet adalah sebuah jaringan komputer yang menggunakan jaringan protokol dan arti kata things dapat diartikan sebagai objek fisik[13]. Objek objek tersebut misal sensor data yang terbaca oleh sensor dapat dikirim melalui internet. Dari data pembacaan sensor yang sudah dikirim melalui internet maka memerlukan sebuah penyajian yang dapat dimengerti oleh pengguna agar dapat mempermudah modul pertukaran informasi Antara Bahasa analod sensor dengan Bahasa digital server atau aplikasi yang dapat dipahami oleh pengguna aplikasi [6].

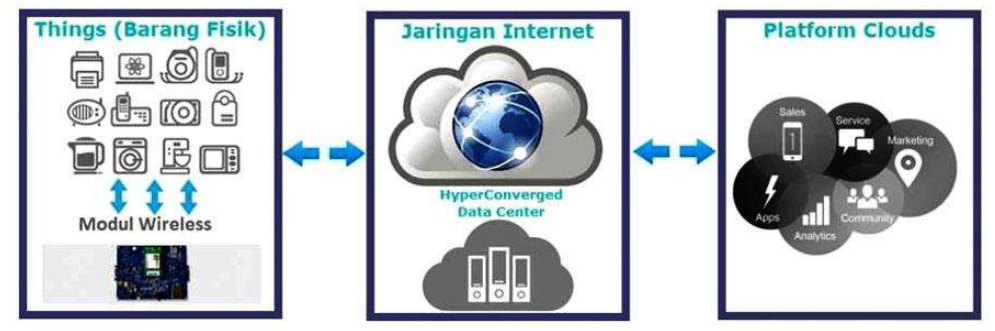

Gambar 2. Internet of Things

(sumber : myspsolution.com)

\subsubsection{NodeMCU}

NodeMCU adalah platform sumber IOT terbuka dan itu dibangun di ESP8266 terintegrasi modul Wi-Fi[15]. Hal ini juga melibatkan dengan firmware yang berjalan pada Wi-Fi ESP8266 sistem pada chip dan terdiri dari 17 tujuan umum pin input / output dalam, 10 pin pin digital dan 1 analogi pin. Dengan menggunakan NodeMCU itu mengembangkan platform komunikasi untuk hardware dan software modul.[7] 


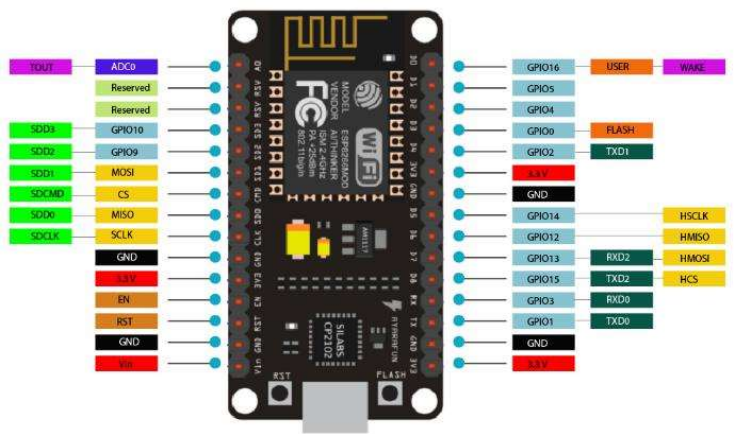

Gambar 3. NodeMCU

(sumber : create.arduino.cc)

\subsubsection{Sensor Soil Moisture(Sensor Kelembapan Tanah)}

Moisture sensor adalah sensor kelembaban yang dapat mendeteksi kelembaban dalam tanah. Sensor ini sangat sederhana, tetapi ideal untuk memantau taman kota, atau tingkat air pada tanaman dipekarangan rumah. Sensor ini terdiri dua probe untuk melewatkan arus melalui tanah, kemudian membaca resistansinya untuk mendapatkan nilai tingkat kelembaban. Semakin banyak air membuat tanah lebih mudah menghantarkan listrik (resistansi kecil), sedangkan tanah yang kering sangat sulit menghantarkan listrik (resistansi besar)[8].

Hasil output dari sensor kelembapan tanah berupa ADC value yang merupakan nilai analog dari 0 sampai 1023[15]. Melihat dari kebutuhan kelembapan tanah pada tanaman cabai berkisar antara $60 \%$ sampai $80 \%$ maka nilai dari $\mathrm{ADC}$ value di rubah menjadi nilai presentase. Untuk merubah nilai ADC value menjadi presentase dapat digunakan rumus sebagai berikut :

$$
\text { Kelembapan Tanah }=\left(100-\left(\left(\frac{\text { ADC Value }}{1023}\right) \times 100\right)\right.
$$

Keterangan :

ADC Value : Inputan digital pin pada Arduino

\section{HASIL DAN PEMBAHASAN}

Tahapan awal dalam penelitian ini adalah melakukan Analisa kebutuhan sistem. Analisa ini dilakukan dengan komunikasi dengan calon pengguna perangkat lunak yang akan dibangun. Proses komunikasi berfokus untuk mengetahui dari proses bisnis yang ada saat ini dan menggali masalah yang dihadapi oleh pengguna saat ini. Hasil dari Analisa data, peneliti melakukan pengolahan data dan dihasilkan sebuah kesimpulan dari kebutuhan fungsional dan non fungsional dari proses tersebut.

Setelah menetapkan kebutuhan fungsional peneliti melakukan perancangan perangkat keras sesui kebutuhan fungsional sistem yang saling terhubung dan terintegrasi. Dari Analisa rancangan ini dibuatlah pemodelan arsitektur perangkat lunak, pemodelan interaksi sistem dengan user serta mock up perangkat lunak. Berikut ini merupakan desain arsitektur perangkat lunak yang akan dibangun.

Pembahasan terhadap hasil penelitian dan pengujian yang diperoleh disajikan dalam bentuk uraian teoritik, baik secara kualitatif maupun kuantitatif. Hasil percobaan sebaiknya ditampilkan dalam berupa grafik atau pun tabel. Untuk grafik dapat mengikuti format untuk diagram dan gambar. 


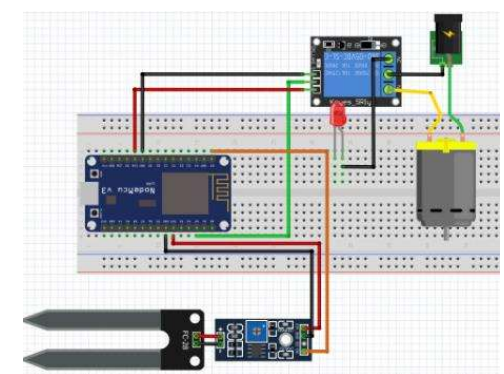

Gambar 4. Arsitektur irigasi berbasis IoT (Internet of Things).

(sumber : dokumentasi peneliti)

Pada gambar diatas terlihat beberapa perangkat keras yang diguakan dalam sistem irigasi berbasis IoT. NodeMCU berfungsi sebagai perangkat yang mengintergrasikan dari sensor kelembapan tanah dengan module relay untuk menghidupkan pompa irigasi. NodeMCU dilengkapi dengan Wifi sehingga dapat berjalan dalam jaringan internet. Sensor kelembanpan tanah berfungsi untuk mendeteksi kadar kelembangan tanah yang akan dikirim ke NodeMCU sehingga NodeMCU dapat mengirimlkan sinyal ke relay untuk menyalakan dan mematikan pompa irigasi secara otomatis. Selain pompa irigasi dapat menyala otomatis, pengguna juga dapat menghidupkan atau mematikan pompa secara manual melalui smartphone android pengguna yang terhubung ke jaringan internet dengan NodeMCU.

Dengan desain arsitektur diatas pengguna dapat menyalakan pompa tanpa harus pergi ke lokasi tanaman. Sehingga pengguna akan dapat lebih membuat perencanaan yang baik secara finansial maupaun alokasi ke tempat instalasi pompa tersebut.

Untuk memahami terkait aliran proses yang ada dalam sistem irigasi berbasis IoT, peneliti menginteprestasikan aliran proses menggunakan diagram alir. Aliran proses sistem ditunjukkan pada gambar 5 .

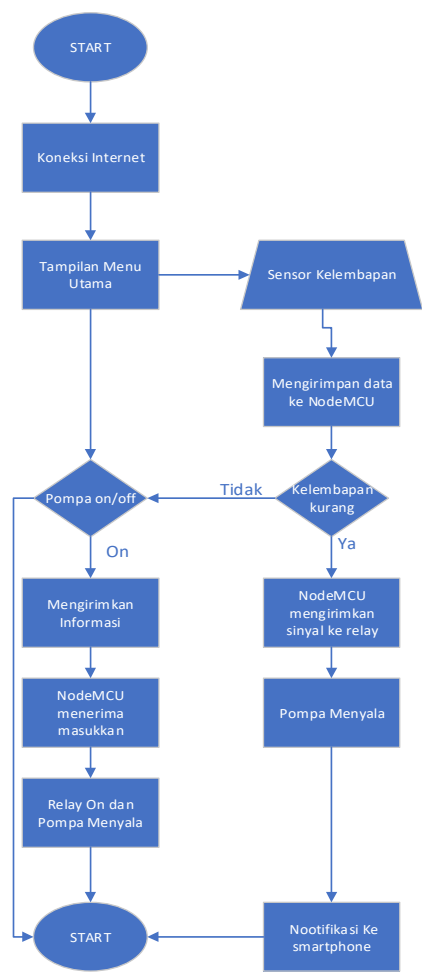

Gambar 5. Diagram alir irigasi berbasis IoT

Pada gambar 5 terlihat aliran diawali dengan set up dari perangkat smartphone yang telah terinstall aplikasi serta terkoneksi dengan internet. Tampilan menu dari sistem tersebut terlihat dua 
menu yaitu monitoring kelembapan tanah dan control pompa irigasi. Pada control pompa irigasi pengguna melakukan interaksi dari pengguna, maka secara otomatis akan memerikan notifikasi ke sistem ke smartphone yang telah terinstall aplikasi tersebut. Untuk memodelkan bagaimana pengguna berinteraksi dengan sistem gambar 6 adalah pemodelan dari usecase sistem tersebut.

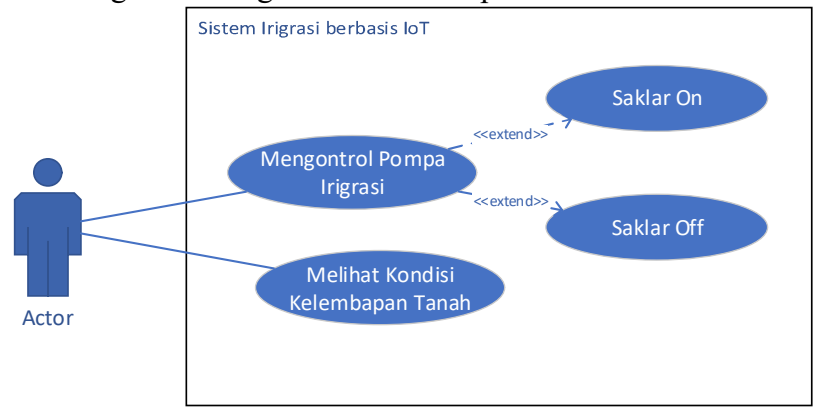

Gambar 6. Desain Interaksi pengguna dengan sistem.

Setelah sistem dimodelkan dengan jelas dalam bentuk arsitektur sistem, aliran proses serta model interaksi maka dibuat bentuk aplikasi yang terinstall pada smartphone, peneliti membuat desain mock up dari sistem tersebut yang dapat dilihat pada gambar 7.

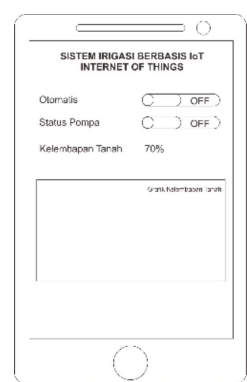

Gambar 7. Desain Interface aplikasi

Dari semua pemodel yang telah dibuat kemudian peneliti membuat aplikasi berbasis android dan merakit komponen perangkat keras sesuai desain sistem yang telah dibuat. Setelah perangkat keras dan perangkat lunak dibuat setelah itu dibuat pengujian terhadap perangkat. Perakitan perangkat keras yang digunakan untuk pengujian dapat dilihat pada gambar 8 .

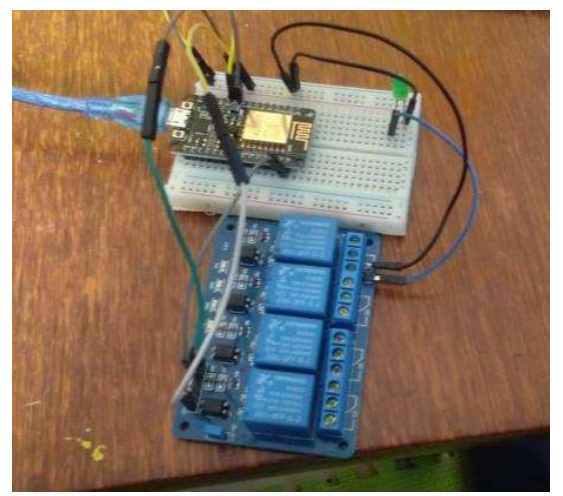

Gambar 8. Instalasi Prototype sistem irigasi berbasi IoT (sumber : dokumentasi peneliti)

Pada gambar 7 dan 8 terlihat perangkat lunak dan rangkaian perangkat keras yang saling terhubung untuk memasitkkan sistem berjalan sesuai dengan kebutuhan pengguna. Pengujian control pompa irigasi dapat dilihat dengan mengukur jeda dari perintah di smartphone dengan 
penyelesaian perintah yang ada diperangkat keras. Table 1 memperlihatkan waktu, jeda delay dan keterangan hasil perintah.

Tabel 1. Hasil pengujian control pompa irigasi

\begin{tabular}{cccc}
\hline No. & Waktu & Jeda Delay & Keterangan \\
\hline $\mathbf{1 .}$ & $08.00 .00-08.00 .05$ & 5 detik & Pompa irigasi menyala \\
\hline $\mathbf{2 .}$ & $10.25 .02-10.21 .05$ & 3 detik & Pompa irigasi menyala \\
\hline $\mathbf{3 .}$ & $12.10 .04-12.10 .07$ & 3 detik & Pompa irigasi menyala \\
\hline $\mathbf{4 .}$ & $14.20 .20-14.20 .30$ & 10 detik & Pompa irigasi menyala \\
\hline $\mathbf{5 .}$ & $16.00 .33-16.00 .36$ & 3 detik & Pompa irigasi menyala \\
\hline \multicolumn{4}{c}{} \\
\hline
\end{tabular}

Pada tabel 1 terlihat hasil rata-rata delay yang terjadi ketika proses control pompa irigasi selama 4,8 detik. Dengan rata-rata 4,8 detik ini perintah menyalan pompa irigasi di sampaikan dari smartphone ke NodeMCU dan diterukan ke relay.

\section{SIMPULAN}

Karena penelitian ini berfokus pada perancangan sistem, maka disarankan untuk di implementasi, sehingga alat ini dapat bekerja dengan baik dengan kondisi cuaca yang ada di tempat tanaman cabai. Selanjutnya karena terbatas hanya sistem control saja, pengembangan selanjutnya perangkat dibuat lebih smart irigation sehingga pengguna dapat mengetahui apa yang dibutuhkan tanaman cabai tersebut. Sistem cerdas ini seperti penambahan sensor cuaca, keasaman tanah dan lain sebagainya.

\section{SARAN}

Karena penelitian ini berfokus pada perancangan sistem, maka disarankan untuk di implementasi, sehingga alat ini dapat bekerja dengan baik dengan kondisi cuaca yang ada di tempat tanaman cabai. Selanjutnya karena terbatas hanya sistem control saja, pengembangan selanjutnya perangkat dibuat lebih smart irigation sehingga pengguna dapat mengetahui apa yang dibutuhkan tanaman cabai tersebut. Sistem cerdas ini seperti penambahan sensor cuaca, keasaman tanah dan lain sebagainya.

\section{DAFTAR PUSTAKA}

[1] H. D. Setyaningrum, and Saparinto, C,"Panen sayur secara rutin di lahan sempit. Penebar Swadaya Grup",2012.

[2] A. Junaidi, "Internet of Things, Sejarah, Teknologi Dan Penerapannya," J. Ilm. Teknol. Inf., vol.I,no. AUGUST 2015, pp. 62-66, 2016.

[3] R.J. Apsari, R," Monitoring Keamanan Rumah Dengan Menggunakan Mikrokontroler Melalui Web", Jurnal Manajemen Informatika, 8(1), 2018.

[4] L. Setiyani and K.Suhada, K,"'Perancangan Dan Implementasi Iot (Internet Of Things) Pada Smarthome Menggunakan Raspberry Pi Berbasis", Simetris: Jurnal Teknik Mesin, Elektro dan Ilmu Komputer, Vol. 10(2), 459-466.2019.

[5] N. Sumarni, and A. Muharam, "Budidaya tanaman cabai merah. Balai Penelitian Tanaman Sayuran", Lembang,2005.

[6] S. Sitrusta. ," Bermain Dengan Internet Of Things Dan BigData", Politeknik Elektronika Negeri Surabaya, 2016.

[7] B.R. Babu, B. Anudeep, M. Yugma, M.S, Meghana, and S. Swami, S,"Real Time Iot Based Office Automation System Using Nodemcu Esp8266 Module",. International Journal of Research, 6(4), 250-254,2019 
[8] P, Asriya, and M. Yusfi," Rancang Bangun Sistem Monitoring Kelembaban Tanah Menggunakan Wireless Sensor Berbasis Arduino Uno”, Jurnal Fisika Unand, Vol 5(4),pp 327$333,2016$.

[9] S. Noorhadi,"Kajian pemberian air dan mulsa terhadap iklim mikro pada tanaman cabai di tanah entisol," Jurnal ilmu tanah dan lingkungan, Vol 4. 2003

[9] Z. Ardian, and M.T. Tombeng, M. T," Penerapan Teknologi Internet Of Things Sebagai Sistem Monitoring Pada Media Tanaman Menggunakan Cloud Terintegrasi Dan Smartphone", Journal Of Informatics And Computer Science,Vol 6(1), 2020.

[10] C. Chotimah, A. Sofyan,and T. Heiriyani, “ Respon Beberapa Pupuk Bokashi Padat Terhadap Hasil Produksi Tanaman Cabai Rawit Hiyung”,Agroekotek View,Vol 3(1),pp 7-15, 2015

[11] M. N. Fu'ad, A. K. Nalendra, and E. Hastari C, "RANCANG BANGUN WEBSITE TRACER ALUMNI AKN PUTRA SANG FAJAR BLITAR ”, antivirus, vol. 13, no. 2, pp. 90-97, Nov. 2019.

[12] A.K, Nalendra, M. Bilal,and I.Y Setiani,"Sistem Informasi Pemeteaan Kesehatan Ibu dan Anak Untuk Menekan Angka Kematian Pada Bayi”, Jurnal Ekonomi Dan Teknik Informatika, Vol 7(1), pp 45-50, 2019.

[13] Y.J, Hwang, C.L, Wooi, M.N, K. Rohani, K. Mehranzamir, S.N.M Arshad, and N.A. Ahmad, N. A,'Prototyping a RF signal-based lightning warning device using with Internet of Things (IOT) integration", of Physics: Conference Series, Vol. 1432, No. 1, pp. 012078,2020

[14] A. K. Nalendra, M. Mujiono, R Akhsani, R., \& Utama, A. S. W. (2020). Implementasi Algoritma K-Mean dalam Pengelompokan Data Kecelakaan di Kabupaten Kediri. VOCATECH: Vocational Education and Technology Journal, 1(2), 53-60[15]

Jayaysingh, R., David, J., Raaj, M. J. M., Daniel, D., \& BlessyTelagathoti, D. (2020, March). IoT Based Patient Monitoring System Using NodeMCU. In 2020 5th International Conference on Devices, Circuits and Systems (ICDCS) (pp. 240-243). IEEE 